\title{
The Techno-Ecological Practice as the Politics of Ontological Coalitions
}

\author{
Anna Nacher \\ Institute of Audiovisual Arts \\ Faculty of Management and Social \\ Communication \\ Jagiellonian University, Krakow, \\ Poland \\ ul. Bobrzynskiego 45b/69, 30-348 \\ Krakow \\ anna.nacher@uj.edu.pl
}

\begin{abstract}
The paper focuses on the art projects aimed at visualizing (grasping) the physical or biological phenomena through interfaces and / or installations designed specifically for such purpose. Such works often mirror the post-digital condition of our time where the digital technologies constitute the common background for everyday activities, no longer having the allure of "new" and "exciting" (Berry, Dieter et al., 2015). In this process, both the networked technologies of wireless communication and the act of crossing the boundaries between the digital and the physical play the crucial role as the post-digital networked imagery increasingly becomes directly connected to the physical environment. I would like to ponder on the questions of processuality and relationality involved in such instances where the complexity of the hybrid works of art clearly transgresses the paradigm of representationalism (Thrift, 2008; Anderson and Harrison, 2010; Kember and Zylinska, 2012). The particular attention is given to the fact that such artworks bond different ontological realms (discursive, physical, digital) and different agents (human and non-human, carbon-based and software-based) forging "ontological coalitions" (Malafouris, 2013). Throughout the article the mutlirealist and relational perspective is offered, inspired by the propositions of Gilbert Simondon and Etienne Souriau.
\end{abstract}

Based on the research project supported by National Science Centre Poland ("The aesthetics of post-digital imagery: between new materialism and object-oriented philosophy", 2016/21/B/HS2/00746)

Keywords: Post-digital imagining. Techno-ecological practice. Non-representationalism. Relationality.

\section{INTRODUCTION}

In this paper I analyse the techno-ecological art practices, which exemplify the post-digital conditions of our time. The imagery produced in the fully automatic or half-automatic data processing circuits, with minimal or no human intervention, based on the data directly taken from the physical environment, I suggest, calls for the updated theoretical framework. While the significant attention has been paid to the fact that the digital imagery nowadays is grounded in the various forms of data processing (Marie \& Hoelzl, 2015; Bridle, 2011), the approaches that would sufficiently ponder on its processual, relational quality or on the problem of the distributed agencies involved in the process are still missing. Some of the new outlines of the post-digital imagery are, however, aware of its spatial, experiential and relational characteristcs but, again, tend to focus mostly on the data processing and computation (Berry and Dieter, 2015). Yet, as convincingly argued by Adrian Mackenzie (Mackenzie, 2010) even the wireless communication, forming the very backbone of the contemporary media ecology is itself a highly hybrid phenomenon, where processing of digital data compounds with analogue electromagnetic spectrum.

The major shift concerning the image production has already been noticed. What up until now was perceived solely or primarily as the stable representation of the world gives way to the image understood in terms of "the continuous actualization of networked data" or "networked terminal" (Marie and Hoelzl, 2015, loc.146). The human individual authorship and its dominating agency has already 
been questioned and/or coopted within the enviroment imbued with numerous technical entities (including software), yet the nature and function of the non-human actors is still under investigation. These increasingly include both the objects imbued with communicational abilities and the connecting infrastructure, based on the sensor networks and low-range wireless communication (RFID and Bluetooth), known as the internet of things (IoT).

Already at first glance it is clear that we are confronted with a face of communication network and computing technology that differ from the customary concepts developed in reference to the world of individual computers immobilized on desktops and connected with wires into a network with relatively stable parameters. This new shape of computing technology is more and more dispersed and connected to the environment. It is also based on the procedures of the automatic data exchange between data processing software and distributed sensing networks that collect such data directly from the environment. Human activity - be it providing the data, processing it or creating and distributing the content - is just one of the elements of this technosocial community.

Accordingly, it is more adequate to refer to the conditions of "post-digitality", where the digital technologies became ubiquitous and where they constitute the common background for everyday activities, no longer having the allure of "new" and "exciting" (Berry and Dieter, 2015; Cramer, 2018). In this process, both the networked technologies of wireless communication and the act of crossing the boundaries between the digital and the physical play the crucial role. Yet, I propose the analysis of this new visual environment not be limited to the procedures of data processing, in order to acknowledge the complexity of the visual objects' production and circulation within the networked media. It is directly related to the already mentioned shift in computing paradigm. Berry and Dieter describe such shift as follows: "Computation becomes experiential, spatial and materialized in its implementation, embedded within the environment and embodied, part of the texture of life itself but also upon and even within the body. Computation becomes something which operates while one walks around, is touched and touch- able, manipulated and manipulable and interactive and operable through a number of entry-points, surfaces and veneers." (2015, p.3).

Therefore, the aim is to update the theory of digital imagining beyond the obvious limits of representationalism. By the notion of representationalism I understand - following Thrift, Kember and Zylinska and others (Thrift, 2008; Anderson and Harrison, 2010, Kember and
Zylinska, 2012) - the approach that overestimates the isolated acts of representation at the expense of its processuality, technicality of the process and the users' practices contributing to the affective economy of embodied meaning (Nacher, 2016). In addition, within such paradigm the act of representation is often perceived as a cut decisively separating image from reality. In other words, within the paradigm of representationalism, an effect of representation is given a priority over the processes that constitute it - the approach which is often accompanied by equating the visual/semiotic with the intelligible. This often results in treating images as a set of purely symbolic objects, isolated from the broader processes of their production, including technosocial conditions and limitations (often relegated to the margins as additional "context", something to be included in the analysis only incidentally and without the real impact on the core meanings). In my interpretation, I would like to reverse this tendency, which I consider partly inherited from the cultural studies focusing on the more traditional image-bound media and the art criticism concerned predominantly with the formal qualities of the aesthetic objects (despite the strong rejection of this paradigm inspired by conceptual and post-conceptual art).

Overestimating the objects at the expense of the processes is particularly striking when post-digital, networked visual culture is concerned, since it relies upon the dynamic and automated or quasiautomated circulation of content followed by its rapid re-contextualization. Imagery produced within such circuits is the outcome of the data processing, often the data taken directly from physical environments as illustrated in the case of distributed sensing networks. Consequently, the already mentioned paradigm of representationalism obscures the nature of networked image production and limits its understanding, including seeing it as "digital objects" (Hui, 2016). In my pursuit, I seek the new conceptual tools allowing to grasp hybrid, ontologically unstable and at the same time processual nature of postdigital imagery.

\section{TECHNO-ECOLOGICAL PRACTICE AS BONDING ACROSS REALMS}

The examples of post-digital imagining I am going to elaborate on belong to the techno-ecological artistic practice, which involves the broad scope of meanings. It may include any technology-based artworks directly dealing with ecological crisis and degradation of the environment, including the climate change and exhaustion of resources. It can also relate to the ideas of sustainability, resilience and ability to renew and heal the damages done to 
nature. Rasa Smite and Raitis Smits state that "Ecology today can't be reduced to environmental issues alone. Neither can modern technology still be seen as the evil and primary cause of environmental disasters. Instead, there is an urgent need to build a new perspective which we call 'techno-ecological' that takes all this complexity into account." (Smite \& Smits, 2011, p. 144). The proponent of the concept, Eric Kluitenberg, on one hand was inspired by Felix Guattari's transversal thinking as exemplified in his book Three Ecologies (2000), on the other - by Siegfried Zielinski's proposition known as variantology. According to both approaches multiplicity and alteration constitute the very basis of media technologies rather than unification of standards, formats and procedures - the observation which should inspire similar transversality also as far as discourses and reflection surrounding media are concerned. Guattari's transversality allows transgression of the borders separating different domains of reflection, as exemplified by his three ecological registers, including the environment, social relations and human subjectivity. However, according to Guattari, transversality is also aimed at crossing the border between theory and practice. The point he proved valid through his long-time activity at the clinic of La Borde is also significant for the techno-ecological media installations, some of which subscribe to the nascent discipline of art\&science, where advanced research meets the aesthetic response to the scientific problems. Variantology, on the other hand, was offered as the theoretical framework to decolonize the thinking about technological innovation and progress as it proposed to include non-Western epistemic cultures (for instance Arabic-Islam culture) in order to reach the different understanding of media (Zielinski and Wagnermeier, 2005). Therefore, it provided the ground to include variety of modifications and diversions occurring when the main concepts of media theory are traced across the disciplines and cultures. It is to replace or counteract thinking in terms of linear progress and technical standardization as the basic conceptualization of media culture at large. Variantology, based on Foucault's concept of geneaology, reaches out to the disciplines long considered as having no direct impact on discourse of contemporary media, such as theology, art theory, natural science and classical philology. It also offers the methodological background to forge stronger relationships between media, technical culture, natural phenomena and sociocultural relations. Kluitenberg opens his text with the statement that "Technology can no longer be understood as an alterity (otherness) that stand in opposition to biological and social relations." (Kluitenberg, 2011, p. 11). Such perspective - based in part on the line of argumentation in Latour's The Politics of Nature proposes dismantling the conceptual borders separating the natural and the artificial through more in-depth attention to its discoursive economies, histories and functions. As, (following Latour) Kluitenberg reminds us, 'nature' is not a stable category but rather the effect of conflation of the whole plethora of micro-agencies which often get assigned the passive role while in fact they are capable of forging the net of meaningful relations. Such vision is also underlined by the history of the modern techno-scientific research practices, which on their part transform "the natural" and blur the neat distinctions upon which the very modernist concept of nature as independent from the artificial and manmade is founded.

The remote sensor-based networks implemented in the wilderness in a wide array of contexts (scientific, artistic, managerial) is one of the areas where the co-evolving of nature and technology is best observed. It has been recently extensively analysed by Jennifer Gabrys, who regarded such networks in the perspective of their mutual co-development with the notion of environment. She proposes the particularly useful notion of the "becoming environmental of computation" (Gabrys, 2016, loc.324), which again underlines the technological shift occurring with the implementation of various configurations of ubiquitous computing. At the same time, inspired by the Whiteheadian notion of concrescence (which basically mean co-formation of entities beyond the idea of adding up already preformed, stable subjects), Gabrys points out that "environments are not fixed backdrops for the implementation of sensor devices, but rather are involved in processes of becoming along with these technologies. Environment is not the ground or fundamental condition against which sensor technologies form, but rather develops with and through sensor technologies as they take hold and concresce in these contexts." (2015, loc. 324). Furthermore, she underlines that in the process of concrescene productive of the environments and entities, the generation of relations which bind them is as important. As I will demonstrate, the coevolution of the environment where the border between natural and artificial is constantly blurred and therefore the different ontological domains constantly cross-polinate, is of crucial importance..

\subsection{Media installation as "ontological coalitions"}

One of the best illustrations of how the ontological coalition is forged with techno-ecological art practice comes with Mirage (2014) by Ralf Baecker, awarded with Prix Ars Electronica's Honorary Mention in the category of Hybrid Art in 2015. The artwork consists of the specific device, designed and built by the artist, beaming the light pattern which is synthesised landscape based on the processing the data gained through magnetometer measuring the magnetic field 
of the Earth and its interactions with the sun's activity. The information is then analysed by the unsupervised learning algorithm which successively presents the variations based on the performed analysis, which is likened to "dreaming". The algorithm is inspired by the Helmholtz Machine, artificial neural network capable of generating the models of the original datasets and designed to look for hidden data structures. In consequence, the artwork is not only a way to directly measure the fluctuations of Earth's electromagnetic field, let alone make it visible, but it can also be seen as the form of the of collective "phantasy". The agencies and actors inscribed in the process (and capable of "dreaming" activity) are many and multifarious: the natural forces (electromagnetism), human observers (the audience) and silicon-based components modelled after neuronal activity (learning algorithm).

Multiple agencies and actors (including the microorganisms) are also involved in the production of Biotricity (2014 - ongoing), the installation conceived and built by Rasa Smite, Raitis Smits and the collaborating team of scientists and media designers at the Riga's RIXC Center for New Media. Here the bacteria present in various environments: mud, waste, soil and also inside of our bodies, capable of releasing the free electrons under the harsh circumstances of the milieus deprived of oxygen, are used as the source of electric energy. It is the outcome of the research carried out for several years at the RIXC Center for New Media, where the artists and scientists experimented with microbial fuel cells seeking the possibilities to create the sustainable ways of overcoming the crises caused by the extensive use of fossil fuels. The installation has been presented on several occasions, including the "Open Fields" RIXC Art Science Festival in Riga in 2016, the "Open Codes" exhibition at the Zentrum fuer Kunst und Media in Karlsruhe (2018) and the Venice Architecture Biennale 2018 (the latest incarnation of the project, known as the Swamp Radio is on display at the Lithuanian Pavillion). The installation is usually presented as the sonic and visual experiments, where the fluctuations in the electricity produced by the two "bacteria batteries" is rendered as sonic structures which manipulate the visualization of the real-time data, available as the image on the screen (at the "Open Fields" Festival in 2016 the data were taken directly from the pond just outside the Latvian capital).

Two media installations described above evolve on the crossroads of the multiple agencies and realities of the physical and the digital domains. As such, they are capable of forging the "ontological coalitions" which bridge different ontological realms, especially those falling in two usually juxtaposed categories of the physical (associated with the real and the material) and digital (often perceived as immaterial and purely discursive). The notion has been coined by Colin Renfrew and Lambert Malafouris (2010) and later developed by Malafouris (2013) to better analyse "the cognitive ecologies of the material engagement" (Malafouris, 2013, p. 21). Both authors are primarily concerned with grasping the relationality of the robust engagement of the human mind in the embodied cognition. Therefore Malafouris, while describing the walking stick of a blind person, defines "ontological coalition" as "the gray zone of material engagement" (Malafouris, 2013 , p. 5). Elsewhere he clarifies it as "the zone, in which brains, bodies, and things conflate, mutually catalyzing and constituting one another" (Malafouris, 2004, p. 55). In my opinion, the concept can help to better grasp the process of intensive datafication of the physical reality, where digital data and the code increasingly permeate the space, perceived until recently as "natural". In fact, what happens in the process can be likened to conflation of "brains, bodies and things" as the sphere of representation (natural phenomena translated into digital data operated with the code, i.e. brain) meshes with the physical world (i.e. bodies and things). Therefore, the term "ontological coalition" itself indicates both the distributed cognition on the crossroads of the human and non-human and the mutual permeation of the physical objects with the mental and imaginary phenomena. It highlights the complexity of agency perceived more as the quality of the whole environment than of the individual cognizant entity, offering the much needed critique of the cognition understood exclusively as the operation on symbols. The concept of "ontological coalition" emphasizes the fusion of physical world and data processing (including the forms of artificial intelligence).

However, to modify its still too much humancentered angle, I propose to understand the ontological coalition first and foremost as the ability to bridge and articulate different ontological domains, which in case of both artworks mentioned above means essentially that the aesthetic object (be it the imagery or the soundwave) constitutes a continuum altogether with the natural phenomena addressed by the artists and the digital objects enabling the mediation (such as intelligent algorithms, data processing tools and communication protocols). I am following Matthew Fuller's remark who understands the concept of such coalition as linking "different states of matter organized as machines, minds, ambiences, objects, producing complex states of mentations and sensations as bodies" (Fuller, 2013, p. xxiv). At the same time I would rather emphasize its processual quality. Therefore, I see it rather as a transversal process, through which the phenomena are transferred from one type of materiality (the domain of physical reality) to another (the domain of data and code which - although not purely physical - are capable of exerting the impact on the reality 
perceived by the human). Mitchell Whitelaw explains transmateriality as the theoretical perspective comprehending "media and computation as always and everywhere material while maintaining (...) the behavioral illusion of immateriality." (Whitelaw, 2013, p. 230). Therefore, the materiality of technological and organic nonhuman actors needs to be accounted for (sensor networks, wireless communications spectrum, code and algorithms, biological and physical processes as well as microorganisms). Despite such modification, the core idea of the ontological coalition as multiple engagements across the domains of the material and discursive (or the physical and digital) is left intact. The attention is paid not so much to the hybrid character of the ontological coalition itself, understood as the objectlike entity consisting of ingredients from diverse domains and levels of existence, but rather to the movements, transfers and relations occurring through the borders separating those domains.

Simultaneously, I would suggest to probe the concept as the tool to "redefine the material in discursive terms." (Hekman, 2008, p. 88), which would eschew privileging either but rather enabled productive assemblages incorporating human and non-human agencies. The particularly promising modification of the notion of "ontological coalition", the one which would acknowledge both its hybrid nature and the internally dynamic and processual character, seems to occur along the pathways marked by highly relational and processual multiontology proposed by Etienne Souriau (and to some extent by Gilbert Simondon). To explain the idea of multiontology and its productive quality I will briefly refer to the Souriau's ideas of different modes of existance, supported by the notion of instauration (which in case of the both media installations, Mirage and Biotricity, could supplant the term "production" or "creation"). In other words, coevolution of the entities forming the new environments (be it natural, digital or imaginational) can be interpreted in terms of its instauration.

\section{NEGOTIATING THE DIFFERENT MODES OF EXISTENCE}

In the case of Baecker's Mirage, adding the algorithmic agency on the top of an already complex milieu (electromagnetic field and the digital components of the installation) introduces the highly transversal aesthetic strategy. Simondon explaining his term of transduction - refers both to the natural process of crystallization and to societal, artificial and cultural practice of brick making (Simondon, 1989), implying the possibilities to connect heterogeneous and incompatible domains (including hybrid, material-discursive entities). From this perspective, the Baecker's synthesised landscape "dreamt" by the algorithm can be understood as the vehicle that transits across seemingly incoherent ontological spheres: natural (electromagnetic field), mechanical (the specifically designed apparatus) and digital (data on Earth's electromagnetic field's fluctuations and the generative algorithm). The latter in fact is a discursive-material hybrid, according to the transmaterial approach represented by Baecker also in his previous works which bring to light the material aspects of computation (for example Irrational Computing, 2011). Such a perspective provides a better ground for understanding the material conditions of the datafied physical world, where the physical and the digital is fused. Baecker's Mirage generates the image (the dynamic pattern of red light) which coexists with the world in the way it is synthesized as based on the data obtained from the environment. At the same time, it transits the ontologically distant domains: that of physical materiality and that of abstraction and "dreaming". In this case, the red, fluctuating wavelike form, generated on the top of the scientificallylooking apparatus, visible while approaching Mirage, is to be understood as the part of the assemblage (where human imagination, geomagnetic field and computational procedures are bounded together in their capability to influence each other) or, better yet, as the vehicle allowing the transduction occurring between physical reality of the universe, the digital domain mediating it and the space of the gallery itself. It is the image itself which bonds all the dispersed ontological domains, which form the ontological coalition. Furthermore, to some extent all the imagery produced through sensor networks of various kinds shares such ability to cross the various registers of materiality. Such observation provides the fertile ground for understanding post-digitality as primarily the sphere of mediation that stretches between the physical and the digital. It inspires the wider debate on the multiple and varied agencies involved in the instauration of the post-digital and its multiontological quality.

Asking for the status of diverse ontological domains involved in techno--ecological post art practices, it is worthy to point out that already in 1943 Etienne Souriau asked: "Is it true that one can only exist in half-measures? That all things, a stone as much as a soul, from the moment of entering it, are equal in their existence?" (Souriau, 2015, p. 109. Referred to by Deleuze \& Guattari in their What is philosophy? Souriau was considered primarily an aesthetician, a specialist in theory of art and early film studies (French filmology). However, Bruno Latour wrote that "Souriau is a metaphysician who always operates on the privileged 'field' (if I may say so) of the reception of the artwork" (2011, p. 309). Indeed, The Different Modes... line of argumentation is clear 
in at least one regard: Souriau proposes the ontological pluralism, not dissimilar to James' multirealism. He is convinced that in order to seriously engage the idea of multiplicity, one has to start approaching it in terms of radical, as Zielinski has put it, variantology.

The different modes he categorised and catalogued are to be respected on their own terms, yet their relational and productive qualities must be kept in mind at the same time. Souriau's proposition is strongly inspired by the radically relational and processual William James' "philosophy of prepositions". Bruno Latour summarises Souriau's oeuvre in one question: "can we perhaps try alteration as a mode of subsistence, instead of always going to look for the substance lying beneath the alterations?" (Latour, 2011, p. 313). He conceived of two "genres" of the existence: aseity which is the independent existence in itself and abaleity which, on the contrary, is the existence in the network of references and relations. Yet, as Catherine Noske explains: "But the two function interactively ... Thus, we understand our own human existence as aseitic, biologically independent, in responding to our empirical experience of reality. But these experiences and the world around us have their own abaleitic existence, which supports ours in our relations to them." (Noske, 2015). Those two genres of existence, as Noske underlines, function in relation to each other. At the same time she points out to the fact that here we deal with "co-birth of subject and object" (Noske, 2015; Fruteau de Laclos 2011) through the process of instauration. Basically, instauration signifies the moment of coming into being which at the same time is the particular mode of existence. As Noske sums it up: instauration "emerges as the natural process of existential agency" (Noske, 2015). Such "coming into being" can be understood as the co-evolution of the environment, where the components and entities do not precede the relations forged between them, which enable their very evolution. From this point of view, in both Baecker's Mirage and Smits and Smite's Biotricity, there is no clear line between the aesthetic object presented at the gallery, the natural phenomena, the environmental data and the procedures of its processing enabling the production of the media installation. The installation comes into being as oscillating between abaleitic and aseitic modes of existence. The former means that it is inscribed into the set of relations forged within ontological coalition stretching from the natural phenomena through the data captured from the environment to its processing and the latter - that it is perceived as the work of art in its "objecthood". It also signifies that the whole chain of agencies is set in motion and that the creative process propagates as instauration, the mode of coming into existence as the productive force rather than the entity or the object.
It is precisely the co-evolution of the internally dynamic environment that comes into existence when the red light pattern based on the data representing the fluctuations of Earth's electromagnetic field and the intervention of the intelligent algorithm is generated by the Baecker's installation. The new environment is slowly evolving in front of us, where all the elements co-influence the trajectory of their respective evolutions. Those elements include natural phenomena (electromagnetic field responding to the Sun's activity), technical apparatus built by artist himself as the installation, data gathered from the environment, code synthesizing the visual component and the intelligent algorithm successively presenting the variations of the light pattern based on the performed analysis, which is likened to "dreaming". The visual component - the synthesized, constantly morphing and modifying glowing landscape composed of red lines - in fact is performing the double task: that of making the normally imperceptible natural phenomena visible and that of bonding the different modes of existence (the one formed by the relations and the one based on the objecthood of the object) and ontologically heterogenous domains of the material, digital and imaginational.

\section{CONCLUSIONS}

Considering the highly hybrid nature of the imagery generated with the post-digital, techno-ecological media art practices, I employed the theoretical framework which accommodates the internally dynamic force of the images born between and across different ontological realms, which they at the same time link together. I proposed to understand those images - beyond the confines of representationalism - as first and foremost the means to forge the ontological coalitions that encompass the plethora of agencies and actors, including natural forces, electromagnetic spectrum, digital objects and microorganism. As such, they actively enact the process of instauration, where they function as interrelated, relational entities, always meshed in the wide network of the ontologically varying actors.

\section{REFERENCES}

Anderson B., Harrison P. (2010) Taking-Place: Non-Representational Theories and Geography. Farnham - Burlington: Ashgate. 
Berry M. D., Dieter M. (2015) Postdigital

Aesthetics. Art, Computation and Design. New York: Palgrave Macmillan.

Bridle J. (2011) New Aesthetic.

http://www.riglondon.com/blog/2011/05/06/thenew-aesthetic/ (retrieved September 12, 2014, not available anymore).

Cramer F. (2018) Post-Digital Writing In: J. Tabbi (ed.). The Bloomsbury Handbook of Electronic Literature. London - Oxford: Bloomsbury Academic. 361-371.

Fruteau de Laclos F. (2011/12) Les voies de l'instauration: Souriau chez les contemporaines, Critique, no. 775. 931-948.

Fuller, M. (2013) Foreword In Ekman, U. (ed.). Throughout. Art and Culture Emerging with Ubiquitous Computing. Cambridge MA: MIT Press.xi - xxxi.

Gabrys J. (2016) Program Earth. Environmental Sensing Technology and the Making of a Computational Planet. Minneapolis and London: University of Minnesota Press,

Hekman, S. (2008), Constructing the Ballast: An Ontology for Feminism In Alaimo, S. \& Hekman, S. (eds.) Material Feminisms. Bloomington \& Indianapolis: Indiana University Press. 86-118.

Hui Y. (2016) On the Existence of Digital Objects. Minneapolis and London: University of Minnesota Press.

Kember S., Żylińska J. (2012) Life After New Media. Mediation as a Vital Process, Cambridge MA - London: MIT Press

Kluitenberg, E. (2012) Techno-Ecologies Inhabiting the Deep-Technological Spheres of Everyday Life In: Smite R., Smits R. \& Kluitenberg E. (Eds.) Techno-Ecologies, Acoustic Space, vol. 11, RIXC Center for New Media Culture and Liepaja University, Riga.

Latour, B (2011), Reflections on Les diffèrent modes d'existence, trans. S. Muecke In Bryant L.R., Srnicek L., Harman G., The Speculative Turn. Continental Materialism and Realism. Melbourne: re:press. 304-334.

Malafouris, L. (2004) The cognitive basis of material engagement: Where brain, body and culture conflate. In DeMarrais E., Gosden C., and Renfrew C. (eds.) Rethinking Materiality: The Engagement of Mind with the Material World.
McDonald Institute for Archaeological Research, UK. 53-62.

Malafouris L. (2013) How Things Shape the Mind. A Theory of Material Engagement. Cambridge MA: MIT Press.

Marie R., Hoelzl I. (2015) Softimage. Towards a New Theory of the Digital Image. Bristol - Chicago: Intellect.

Nacher, A. (2016) Internet of things and automation of imaging: beyond representationalism, communications +1 , vol. 5 (Machine Communication). 1-20. https://scholarworks.umass.edu/cpo/vol5/iss 1/6/ (retrieved June 10, 2018)

Nacher, A. (2017) The creative process as a "dance of agency" - Shelley Jackson's „Snow”: performing literary text with elements In CortesMaduro D. (ed.) Digital Media and Textuality. From Creation to Archiving, Bielefeld: Transcript Verlag 169-187.

Noske, C (2015), Towards the Existential Pluralism. Reading Through the Philosophy of Etienne

Souriau. Cultural Studies Review, vol. 21 no. 1. 3457, online:

http://epress.lib.uts.edu.au/journals/index.php/csrj/a rticle/view/3951/4750 (retrieved June 11, 2018)

Renfrew, C. \& Malafouris, L., Introduction In Renfrew, C. \& Malafouris, L. (eds.), The Cognitive Life of Things. Recasting the Boundaries of the Mind, McDonald Institute Monographs, UK. 1-13.

Simondon, G. (1989) L'individuation psychique et collective. Paris: Editions Aubier.

Smite R. \& Smits, R. (2011) Emerging TechnoEcological Art Practices: Towards Renewable Futures In: C. Apprich, J. B. Slater, A. lles et al. (Eds.), Provocative Alloys: A Post-Media Anthology. Lueneburg: Post-Media Lab \& Mute Books. 142159.

Souriau, E. (2015) The Different Modes of the Existence. trans. E. Beranek, T. Howles, Minneapolis: Univocal.

Thrift N. (2008) Non-representational Theory. Space, Politics, Affect. London - New York: Routledge.

Whitelaw, M. (2013), Transmediality: Presence Aesthetics and the Media Arts in: U. Ekman, Throughout. Art and Culture Emerging with Ubiquitous Computing. Cambridge and London: MIT Press. 223-237. 
Zielinski, S. \& Wagnermeier, S. (eds.) (2005),

Variantology - On Deep Time Relations of Arts,

Sciences and Technologies. Cologne: Verlag der

Buchhandlung König. 